\title{
Motor Intentionality and the Case of Schneider
}

Jensen, Rasmus Thybo

Published in:

Phenomenology and the Cognitive Sciences

DOI:

10.1007/s11097-009-9122-x

Publication date:

2009

Document version

Early version, also known as pre-print

Citation for published version (APA):

Jensen, R. T. (2009). Motor Intentionality and the Case of Schneider. Phenomenology and the Cognitive Sciences, 8(3), 371-388. https://doi.org/10.1007/s11097-009-9122-x 


\title{
Motor intentionality and the case of Schneider
}

\author{
Rasmus Thybo Jensen
}

(C) Springer Science + Business Media B.V. 2009

\begin{abstract}
I argue that Merleau-Ponty's use of the case of Schneider in his arguments for the existence of non-conconceptual and non-representational motor intentionality contains a problematic methodological ambiguity. Motor intentionality is both to be revealed by its perspicuous preservation and by its contrastive impairment in one and the same case. To resolve the resulting contradiction I suggest we emphasize the second of Merleau-Ponty's two lines of argument. I argue that this interpretation is the one in best accordance both with Merleau-Ponty's general methodology and with the empirical case of Schneider as it was described by Gelb and Goldstein.
\end{abstract}

Keywords Motor intentionality · Bodily agency $\cdot$ Merleau-Ponty $\cdot$ The case of Schneider· Neuropsychology

\section{Introduction}

In this paper I return to Merleau-Ponty's original arguments for the need to assume a non-representational and non-conceptual practical mode of intentionality called motor intentionality. I argue that we find a problematic ambiguity in MerleauPonty's argumentation. My primary aim is to display the ambiguity as clearly as possible as I believe that once this is done, we will be in a better position to evaluate some recent attempts to appropriate Merleau-Ponty's arguments.

The ambiguity in question was first identified by Richard M. Zaner in a footnote in his book The Problem of Embodiment (1964). Zaner pointed out that there is an apparent inconsistency in Merleau-Ponty's interpretation of certain pathological cases, in particular his interpretation of the Schneider case: the patient is said both to have a preserved and an impaired non-representational familiarity with his own body and his surroundings (Zaner 1964, p. 186). I will argue that what appears as a

R. T. Jensen (ه)

Center of Subjectivity Research \& Sect. for Philosophy, Department of Media,

Cognition and Communication, University of Copenhagen, Copenhagen, Denmark

e-mail: rasmusthybo@yahoo.dk 
contradiction in Merleau-Ponty's text is a symptom of a methodological ambiguity. The apparent contradiction is a product of the fact that Merleau-Ponty uses the case of Schneider in two mutually exclusive ways: motor intentionality is to be revealed both by its perspicuous preservation and by its contrastive impairment in one and the same case. This double use of the Schneider case has received very little if any critical discussion in the literature. ${ }^{1}$ It does, however, manifest itself in the fact that we find interpretations of Merleau-Ponty's notion of motor intentionality that more or less inadvertently opt for one of the two diverging lines of argumentation that are available in Merleau-Ponty's text.

Sean Kelly interprets Schneider as a case of 'a kind of pure motor intentionality' and, in line with Merleau-Ponty's first line of argument, he argues that the unreflective, skilful coping activities of normal subjects involve the same kind of experience as that which is intact in the pathological case (Kelly 2000, p. 168, Kelly 2004 p. 75). In contrast, Hubert Dreyfus, in his most recent writing on motor intentionality, follows Merleau-Ponty's second line of argument when he emphasizes the differences between a pathological version and a normal version of motor intentionality (Dreyfus 2007a, p. 64). ${ }^{2}$ Dreyfus notes that we must work with such a differentiation of the notion of motor intentionality because, while motor intentionality is, according to Merleau-Ponty, what Schneider lacks, we must also assume that Schneider possesses it in at least a minimal form if we are to make intelligible his ability to flexibly engage in activities such as the wallet-making he worked at while in rehabilitation (Dreyfus 2007a, p. 63). ${ }^{3}$ A prima facie reason for a preference for the second line of argument chosen by Dreyfus is provided by the fact that it is in the context of this line of argument that Merleau-Ponty first introduces the notion of motor intentionality (Merleau-Ponty 1981, p. 110 / 1945, p. 128). But, as we shall see, Kelly's interpretation is not without justification and MerleauPonty's text is certainly in need of clarification. In fact, once we compare MerleauPonty's text with Goldstein's original descriptions, we discover that Merleau-Ponty's first line of argument involves an unfortunate misrepresentation of parts of Goldstein's work.

\footnotetext{
${ }^{1}$ Siewert comes close to making the problematic double use of the Schneider case explicit. He notes that though the Schneider case is supposed to bring motor intentionality to light, i.e. make it evident by its perspicuous preservation, it is exactly taken to be present also in the normal execution of spontaneous actions that prove so difficult for Schneider (Siewert 2005, p. 273). Braddock has also noted how the 'practical, embodied knowledge' is said to be missing when so-called abstract movements are to be performed but then returns when Schneider is to perform the 'concrete' actions (Braddock 2001, p. 13). Braddock, however, does not raise this as a problem for a coherent understanding of the case nor as a problem for a coherent interpretation of Merleau-Ponty's text. Finally, Baldwin points to the problem which was identified by Zaner. Baldwin draws attention to the fact that Merleau-Ponty on the one hand seems to argue that Schneider has lost his ability to make sense of his objective body but kept his phenomenal body intact and on the other hand ends up placing Schneider's incapacity 'within' his phenomenal body (Baldwin 2007, p. 97).

${ }^{2}$ Waldenfels also emphasizes Merleau-Ponty's second line of argument concerning Schneider (Waldenfels 2000, ch. 3).

${ }^{3}$ When Dreyfus adds that Schneider is able to perceive stable sizes and shapes he seems to go too far in attributing abilities to Schneider, who was unable to visually recognize the size or shape of objects (Dreyfus 2007a, p. 63).
} 
I argue that the most promising way to disambiguate Merleau-Ponty's analysis is to put the emphasis on the second of the two lines of argument and moderate the conclusion of the first line of argument accordingly. This reading will not only avoid the potential contradiction, it will provide the most coherent reading of the two lines of argument in the context of Merleau-Ponty's general methodological reflections. Furthermore, the reading I propose brings Merleau-Ponty's use of the Schneider case closer to his specific use of other types of neuropsychological disorders. Finally, the reading is the one that is best in line with the overall interpretation of the Schneider case that Merleau-Ponty subsequently develops.

As a background for my exposition of how Zaner's contradiction arises, and for my arguments as to how best to dissolve the contradiction within the framework of Merleau-Ponty's Phenomenology of Perception (1945), I shall first provide a short presentation of the case of Schneider.

\section{The case of Schneider according to Gelb and Goldstein}

During the First World War on the 4 June 1915 the 24 year-old mineworker Johann Schneider, who was serving as a soldier in the German Army, was wounded by mine-splinters in the back of his head and remained unconscious for 4 days (Goldstein and Gelb 1918, p. 9). The exact dimension of his wounds is uncertain but there is general evidence that he suffered from substantial brain injuries (Marotta and Behrmann 2004, p. 634). He was admitted to the Hospital for Brain Injury in Frankfurt in February 1916 where he became the patient of the psychologist Adhémer Gelb and the neurologist Kurt Goldstein (Goldstein and Gelb 1918, p. 9). ${ }^{4}$

In their first paper on the case, Gelb and Goldstein diagnosed Schneider as a case of visual agnosia and they took the case to be of significant theoretical interest as a particularly pure example of the apperceptive kind of visual agnosia (Goldstein and Gelb 1918 p. 137). ${ }^{5}$ The debate about the nature of visual agnosia is ongoing and there is no general consensus as to how we should understand the Schneider case on the basis of modern neuro-psychology. Farah classifies the case of Schneider as a case of apperceptive agnosia in the narrow sense that she, along with Benson and Greenberg, terms "visual form agnosia" (Farah 2004, p. 13). Marotta and Behrmann

\footnotetext{
${ }^{4}$ Schneider recovered to the extent that he could run his own grocery shop from 1932 until 1944 when his house was bombed. After the Second World War he was elected mayor of the village he lived in (cf. Goldenberg 2003, p. 294).

5 The term apperceptive mind-blindness or visual agnosia had been introduced by Lissauer in 1890 who distinguished it from associative visual agnosia (Farah 2004, p. 4). Apperceptive visual agnosia is generally used about patients who have a failure of normal visual object recognition, in spite of relatively preserved elementary visual functions, such as acuity, brightness discrimination and colour vision as well as reasonably well-functioning general cognitive abilities (Farah 2004, pp. 11-12). Associative visual agnosia is used about patients who have a selective impairment in their recognition of visually presented objects, despite an apparently intact visual perception, which is shown in their ability to copy drawings in which they don't recognize the motive (Farah 2004, ch. 6). In contrast with apperceptive visual agnostics the patients suffering from associative visual agnosia are able to describe the shape of the objects seen though they cannot immediately identify the object. Schneider was able to copy drawings but his ability seems not to be based on a visual ability to recognize the shape of objects but rather on an ability to trace the shape via imitating movements (cf. Goldstein and Gelb 1918, p. 121). This conclusion is questioned by Goldenberg (Goldenberg 2003, p. 287).
} 
suggest interpreting the case as a case of what Riddoch and Humphrey calls 'integrative agnosia' (Marotta and Behrmann 2004, p. 636); a notion Farah critiques under the heading of 'associative visual agnosia' (Farah 2004, pp. 78-82).

Disregarding the medical uncertainties I shall now give a short presentation of the parts of Gelb and Goldstein's case report that are most relevant for the two lines of arguments we find in Merleau-Ponty's text. ${ }^{6}$

When Schneider was asked to point to or to grasp his own nose in an experimental setting where he was blindfolded he was unable to perform these tasks in the ordinary, immediate fashion, whereas in ordinary life he would have no visible difficulties in executing such habitual actions as for instance finding a handkerchief in his pocket and putting it to his nose (Goldstein 1923, p. 158). Even when asked to perform such habitual acts with closed eyes he would in general be able to do so (Goldstein 1923 p. 173). In order to account for the dissociation between Schneider's different responses to the motor tasks Goldstein introduces the distinction between abstract and concrete movements as a distinction between isolated, arbitrary movements performed on request and habitual movements performed in the run of everyday life (Goldstein 1923 p. 156). Making a circular movement with the hand in front of oneself in an experimental setting where one is requested to do so is an example of an abstract movement. When Schneider was asked to perform such a circular movement he could not do this in the normal immediate manner. Goldstein describes what happens in the following way: Schneider first sets his whole body in motion and then progressively narrows down the movements to the relevant limbs (Goldstein 1923 p. 157). He then raises his arms and moves them in apparently arbitrary straight or curved lines, until he recognizes, according to Goldstein on kinaesthetic grounds, one of these movements as of the correct shape, after which he promptly completes the circular movement (Goldstein 1923 pp. 158-59). Schneider's difficulties in performing such so-called abstract movements contrasts with his ability to perform habitual movement, such as taking out his handkerchief

\footnotetext{
${ }^{6}$ Several scientists have expressed doubts about the validity of the Schneider case. The neurologist Jonathan Cole writes that he for one has never become clear on what kind of psychiatric problem Schneider suffered from (Cole 2008, p. 27). Cole dubs the tendentious use of pathological cases he finds amongst philosophers the "Schneider" problem. The neurophysiologist Georg Goldenberg has argued that the empirical studies of the case made by Gelb and Goldstein and their associates are useless as science (Goldenberg 2003). He argues that the 'case' is the result of an unhappy alliance between scientists blinded by their enthusiasm for a certain holistic solution to the mind-brain-problem and a patient eager to please. I don't find Goldenberg's arguments convincing. For one thing, as Farah notes, one reason that the neurologists Jung and Bay in 1942 and 1945 were unable to confirm Gelb and Goldstein's findings could simply be the recovery of the patient, the possibility of which is testified to by at least one other similar case-study (Farah 2004, p. 21). Furthermore it was in particular the compensatory tracing movements that Jung and Bay did not find convincing evidence for, but taking into consideration that later, visually impaired patients have spontaneously adopted similar tracing strategies it seems unlikely that Schneider should have originally invented the behaviour to satisfy the scientists (Farah 2004, p. 12, Marotta and Behrmann 2004, p. 635). Concerning the alledged incoherence of Gelb and Goldstein's case-report Goldenberg seems too quick when he concludes that Gelb and Goldstein present contradicting evidence concerning Schneider's use of tracing movements in reading (Goldenberg 2003, p. 285). What Goldenberg points to as revealing their incompetence is exactly noticed by Gelb and Goldstein and they provide a coherent explanation of the relevant facts, which Goldenberg does not take into consideration (cf. Goldstein and Gelb 1918, pp. 81-83). See Marotta and Behrmann (2004) for a direct response to Goldenberg's arguments and Landis et al. (1982) for a comprehensive comparison of the Schneider case with a more recent case of visual agnosia.
} 
and blowing his nose, the performance of which is according to Goldstein virtually indistinguishable from the performance of a normal person.

In a later paper, Goldstein interprets the combination of a preserved ability to lead the hand to a specific body part in habitual actions and a disturbed ability to point out locations of the body on request as an expression of a dissociation of what he calls a grasping attitude and a pointing attitude (Goldstein 1971 [1931]). The distinction between the two attitudes is not to be understood as a distinction between two kinds of movements which can be differentiated by the physical position of the hand in relation to the body. Two movements that qua physical movements appear as indistinguishable, at least to the naked eye, might nevertheless be carried out in two different attitudes. Goldstein claims that without the assumption of such two different attitudes and of their possible dissociation the behaviour of Schneider and other patients with brain damage will remain unintelligible (Goldstein 1971 [1931] p. 264).

The distinction between the grasping attitude and the pointing attitude is an instance of the general distinction Gelb and Goldstein make between what they call a concrete and an abstract attitude. Not only goal-oriented movements but also for instance ways of perceiving and of understanding language can be found in concrete and in abstract versions. The concrete and the abstract attitudes are to be understood as "capacity levels of the total personality" and not as isolated specific capacities (Goldstein and Scheerer 1964 [1941], p.1). Goldstein and Scheerer further emphasize the interdependence between the two attitudes in the normal case:

Although the normal person's behaviour is prevailingly concrete, this concreteness can be considered normal only as long as it is embedded in and co-determined by the abstract attitude. For instance, in the normal person both attitudes are always present in a definite figure-ground relation. (Goldstein and Scheerer, 1964, p. 8)

According to Goldstein and Scheerer, neuro-pathological cases are in general to be understood as different forms of disintegration of the two attitudes, which under normal circumstances are integrated:

In pathology this relation [the figure-ground relation] becomes disorganized, if not disintegrated, into an abnormal condition. (Goldstein and Scheerer, 1964, p. 9)

As we shall see later, this integrative conception of the relation between the concrete and the abstract attitude is adopted by Merleau-Ponty, and Zaner's contradiction arises as a consequence of departing from this model in the first line of argument concerning the Schneider case.

The methodological implications and the explanatory role played by the concepts of a concrete and an abstract attitude are not straightforward. Beyond its usefulness in highlighting the phenomenon of motor intentionality Merleau-Ponty's discussion of the Schneider case constitutes his attempt to work out the general understanding of the subject of psychology that is implied in Gelb and Goldstein's concept formations.

\section{Intellectualism as a theory of action}

In Merleau-Ponty's Phenomenology of Perception the Schneider case is first introduced as an impasse for what we might call an intellectualistic theory of action 
and it is in this part of Merleau-Ponty's discussion that we find the imminent danger of the contradiction that Zaner drew attention to. ${ }^{7}$

As a theory of action the view Merleau-Ponty criticizes under the heading of intellectualism implies that all intentional bodily actions can be analysed in terms of two independent components (Merleau-Ponty 1942, p. 188; Merleau-Ponty 1981, p. 138 , n. $2 / 1945$, p. 161 , n. 1). On the one hand we have the conscious intention representing at a minimum the goal of the action, possibly also the movement to be performed and maybe even the bodily automatisms that are to assure the execution of the action. On the other hand we have the physical movement causally initiated by the representational intention or act of the will. The general claim of intellectualism is that in order to make our ability to perform intentional bodily actions at all intelligible we have to assume that the two components of any bodily intentional action are notionally separable in the sense that we can make them intelligible independently of each other. The body must be understood in terms of parts that stand in merely causal, and so external relations to one another and as such the body is an object that is completely accessible from the third person perspective of natural science (Merleau-Ponty 1981 p. 73 / p. 87). Consciousness must be conceived of in terms of representational content and such content is internal to consciousness in the sense that it is through and through accessible from the first person perspective of the thinking subject (Merleau-Ponty 1942, p. 187; Merleau-Ponty 1981, p. 50 / 1945, p. 62).

Merleau-Ponty's general argument against such an intellectualistic model is that it results in exactly the consequence it was designed to avoid: it makes bodily agency as such unintelligible. The consequence of the dualism of a first - and a third-person perspective is that we can only regard the bodily movements as externally related to our intentions or our willings. The bodily movements are regarded as agency-neutral occurrences, i.e., as events that could, in Hornsby's formulation, have taken place in a world bereft of beings who do things for reasons (Hornsby 1998, p. 393). Consequently the intentions or willings just happen to be the cause of some movements when an actual bodily action is carried out and such intentions cannot depend on the existence of any actual success for their intrinsic intentionality. Merleau-Ponty writes:

The impelling intentions [intentions motrices] of the living creature were converted into objective movements : to the will only an instantaneous fiat was allowed, the execution of the act being entirely given over to a nervous mechanism (Merleau-Ponty 1981, p. 55 / 1945, p. 68)

Using Brewer's apt phrasing we might say that bodily behaviour is reduced to a mentally induced reflex (Brewer 1993, p. 311).

The general problem that Merleau-Ponty draws attention to is that once subjectivity is expelled from the body qua natural organism it becomes, as he puts

\footnotetext{
7 The dialectic oscillation of the chapter on motility in Phenomenology of Perception flows as follows: first a critique of an intellectualistic conception of psychology (Merleau-Ponty 1981, pp. 103-112 / 1945, pp. 121-130), then the empiricist has a go at a merely causal explanation of the Schneider case (MerleauPonty 1981 pp. 112-120 / pp. 130-140), the criticism of which leads to the revival of intellectualism (Merleau-Ponty 1981 pp. 120-126/pp. 140-148). The final defeat of intellectualism is said to justify the return of naturalism unless a new method is provided (Merleau-Ponty 1981 p. 126 / p. 147).
} 
it, barely conceivable how the subject is to re-enter nature understood as the realm of occurrences ruled by the natural laws discovered by natural science (Merleau-Ponty 1942, p. 177). If we rest within the framework of intellectualism we are forced to assume some magical operation by means of which the representations can set in motion precisely the third-person objective processes needed to bring about the desired outcome (Merleau-Ponty 1981, 138, n. 2 / 1945, p. 161, n. 1). I suspect that what Merleau-Ponty displays as the fundamental problem of an intellectualistic theory of action is a problem that will haunt all accounts of bodily agency that conceive of our bodily movements as mere outputs of the mind, i.e., as susceptible to a purely natural-scientific understanding. If we attempt to build up a notion of bodily agency via a supposedly agency-neutral notion of bodily motility and a notion of intentions as having a supposedly movement-independent representational content, we will have a hard time making it intelligible how it can be within the power of an agent to move in the ways appropriate in order to execute an intention. On such a picture, the bodily capacity to move is not a capacity of the agent but of the body understood as a locus of agency-neutral occurrences amenable to a natural scientific explanation. ${ }^{8}$

\section{Intellectualism and the case of Schneider}

It is a consequence of the intellectualistic theory of action that any decrease in the ability to perform certain kinds of bodily actions that are not caused by changes in extra-bodily circumstances must be due to at least one of two factors: a change in the representational capacities of the subject or a change in the purely physiological enabling conditions (Merleau-Ponty 1981 p. 120 / p. 140). If I forget my PIN-code my inability to use my credit card is a consequence of a change in my representational capacities. If my arm is 'sleeping' my inability to raise my arm could, according to intellectualism, be due to a purely physiological change. Accordingly, intellectualism is committed to the claim that a representational consciousness is a necessary and sufficient condition for the possibility of performing intentional actions in the normal immediate way, given that all purely physiological and extra-bodily enabling conditions are fulfilled. We can call the two sides of the commitment of intellectualism, the Necessity Thesis and the Sufficiency Thesis. The two lines of argument concerning Schneider which give rise to the internal tension in Merleau-Ponty's text each target one of the two theses.

The first line of argument focuses on the preserved ability of Schneider to engage in concrete behaviour and carry out concrete movements (Merleau-Ponty $1981 \mathrm{pp}$. 103-106 / pp. 120-124). This line argues that a representational awareness of the spatial location of one's own body and of surrounding objects is not necessary for a grasping to be directed towards such objects. I shall refer to this first line of argument as the Argument from Concrete Behaviour. The second line of

\footnotetext{
${ }^{8}$ That the attempt to account for bodily agency via the idea of agency-neutral movements generates a general problem of making bodily agency intelligible at all has been suggested by McDowell and is argued by Hornsby (McDowell 1994, pp. 89-91; Hornsby 1997, pp. 93-110). For a recent survey of the widespread assumption of such agency-neutrality within modern theories of action and for a critique of the assumption see Grünbaum (2008).
} 
argumentation focuses on the impaired ability of Schneider to engage in abstract behaviour and perform abstract movements (Merleau-Ponty 1981 107-112 / pp. 124-128). It argues that a representational awareness of a movement to be carried out, paired with a physical availability of the movement, is not sufficient for the normal, swift execution of such movements. This second line of argument I shall refer to as the Argument from Abstract Behaviour. In the following two sections I will reconstruct the two arguments separately in order to make explicit the negative conclusions of each line of argument.

\section{The argument from concrete behaviour}

In the first instance Merleau-Ponty formulates the impasse confronting the intellectualist in the following manner:

If I know where my nose is when it is a question of holding it, how can I not know where it is when it is a matter of pointing to it? (Merleau-Ponty 1981, p. 104 / 1945, p. 120)

In this formulation in the first person Merleau-Ponty refers to a patient other than Schneider who was not even able to grasp his nose on command (Merleau-Ponty 1981 p. 103, n. 4 / p. 120, n. 3). The analogous puzzle with regard to Schneider would be: How is it possible that he can know where his nose is when he wants to blow it, but not know it when he is to point to it or to grasp it on demand? Such questions are troublesome for intellectualism because it is committed to the claim that all spatial awareness of an object consists in a conceptual representation of its location in objective space (Merleau-Ponty 1981 p. $104 /$ p. 121). If an objectdirected intentional action aiming at the specific location of one's nose is possible when one is to reach for it, this must, according to intellectualism be partly by virtue of a representation of the location of the nose. This leaves it difficult to understand why a movement which is to be directed towards the same location, but stop only a few centimetres before the nose cannot be successfully carried out. As MerleauPonty notes, it is, after all, the same nervous system and the same muscles that enable both kinds of movements (Merleau-Ponty 1981 pp. 122-123 / p. 142).

Two representations with different content can of course be of the same object. As Merleau-Ponty writes it takes an intellectual synthesis to come to realize that for instance the evening star and the morning star are but two appearances of the same object, called Venus (Merleau-Ponty 1981230 / p. 266). Intellectualism has no need to deny the Fregean distinction between sense and reference and it is not committed to the general idea that all failures of recognizing two representations of one and the same object in one and the same location as representations of the same object in the same location must be failures of rationality. However in the case of a grasping of and a pointing to for instance one's nose, the subject must know that the nose she is to point to is the same object in the same location as the object she is to grasp if we are to make sense of her as capable of trying to perform the two kinds of action. We cannot assume that the patient is not aware of the fact that the nose she is to point to is the same as the one she is to grasp and still maintain that she understands what she is to do in the two cases. Furthermore there is no more reason to think that the patient should lose track of 
the position of the nose between a request of grasping and a request of pointing than there is reason to think that he should lose track of the nose between two acts of grasping. Hence it becomes difficult to see why the spatial representation that, according to intellectualism, must be present if the grasping is an intentional action directed towards the nose should not also make a pointing possible. ${ }^{9}$

Formally speaking, intellectualism is faced with a dilemma. It must either ascribe representational knowledge of the location of the nose to the patient, in which case it has to be admitted that such knowledge is not sufficient for the pointing, or deny that the patient possesses such knowledge, in which case it has to be admitted that such knowledge is not necessary for the intentional action of grasping. A way around the first horn of the dilemma can be found if a claim about a merely physiological difference between the grasping and the pointing could be substantiated. A passage around the second horn can be found if one denies that the grasping of the patient manifests intentionality. Though Merleau-Ponty does not spell out the argument from concrete behaviour in terms of such a dilemma, both these possible responses are more or less explicitly discussed and dismissed in his text.

The idea that it should be a merely physiological impairment of our motility that hinders the patient in successfully carrying out the pointing acts can be ruled out in advance. The dissociation between pointing and grasping as it is described by Goldstein is, as we have seen, not a distinction between two ways of moving and posturing that can be distinguished as two ways of physically moving. A more likely response to the dilemma from the intellectualist would be the attempt to evade the second horn by denying that the grasping of the patient displays genuine intentionality. The intellectualist could argue, as did Goldstein at some point, that when Schneider is capable of whisking away a mosquito from his nose, then this is no different from what we can do in our sleep (Merleau-Ponty 1981 122, n. 1 / p. 142, n. 1). However, the fact that Schneider can perform concrete actions on command and not just when some bodily stimuli is present makes it implausible to regard his behaviour as a matter of simple reflexes or operant behaviour. As Goldstein states, the patients in question perform the grasping movements with some sense of spatial directedness in contrast to other brain-damaged patients whose limbs perform involuntary and forced movements, and also in contrast to the reflex movements of a decapitated frog (Goldstein 1971, p. 273).

In so far as the intellectualist recognizes that the grasping of the patients are instances of object-directed intentional actions and admits that there is no purely physiological explanation of the inability to point, he is caught up in the dilemma. Merleau-Ponty focuses on the second horn of the dilemma and argues that the concrete behaviour of the patient forces the intellectualist to admit that there is way of being directed towards spatial objects that does not require representational awareness of spatial locations. We can see why the intellectualist is under pressure to

\footnotetext{
${ }^{9}$ Bermúdez has proposed a re-interpretation of the Schneider case that reads the case as evidence for the existence of two different ways of representing the location of limbs and of points on one's own body. He argues that the difference between the awareness needed for grasping and the awareness needed for pointing is a difference at the level of sense and not at the level of reference (Bermúdez 2005, p. 305). Bermúdez's position differs from the intellectualist's position by taking the fundamental representation of our body to be non-conceptual. For a critique of Bermúdez's position from a Merleau-Pontian perspective see Gallagher (2003).
} 
make this concession when we consider that intellectualism regards the demonstrative reference to objects as the most basic kind of intentionality and that it regards even the silent pointing to an object as dependent on a prior conceptual understanding of the object (Merleau-Ponty 1942, p. 216; Merleau-Ponty 1981, pp. 120-121/1945, p. 138). By the standards of intellectualism the most plausible explanation of the lack of pointing abilities would be a reference to a disturbance of representational capacities. Consequently, the negative conclusion of the Argument from Concrete Behaviour is the following: Spatial awareness in terms of a conceptual representation of the location of the relevant object is not necessary for the carrying out of object-directed intentional actions.

\section{The argument from abstract behaviour}

When Schneider was asked to make an abstract movement such as a circle in the air, he first had to locate the relevant limb through preparatory movement. Then he raises his arm and moves his hand in apparently arbitrary movements, and only when he recognizes one of these as the beginning of a circle he manages to complete the circle (Goldstein 1923, p. 158). Since Schneider is able to engage in such attempts on demand and since he is able to recognize when he fails and when he succeeds it is difficult to deny that he possesses an intellectual understanding of the conditions of satisfaction of the order given and therefore must be said to have a representational understanding of what he is to do (Merleau-Ponty 1981 p. 110 / 1945, p. 128). Furthermore the fact that Schneider can carry out movements that are similar to the abstract movement qua physical movement, namely, when he engages in concrete movements, speaks against a purely physiological explanation of the difficulties of the patient. Consequently intellectualism is under pressure to give up the Sufficiency Thesis. The negative conclusion of the Argument from Abstract Behaviour is that representational understanding plus a body that, qua physical system, is capable of executing the relevant movements is not sufficient for the performance of certain actions in the normal immediate way.

\section{Zaner's contradiction}

When formulated in terms of such negative conclusions, the two lines of argument are not yet in conflict, they merely respectively target the Necessity Thesis and the Sufficiency Thesis. It is not until we take a closer look at Merleau-Ponty's positive conclusions that a contradiction threatens to make his interpretation unintelligible.

In the first instance Merleau-Ponty argues that we have to assume a nonrepresentational anticipation of the completion or endpoint (terme/fin) of the movement, as that which enables the concrete movements of grasping in Schneider's and related cases (Merleau-Ponty 1981 p. $104 /$ p. 120). In the next instance he argues that we have to assume a non-representational anticipation of the objective (résultat) of the movement, called motor intentionality, as that which is missing in the case of Schneider and which normally enables us to perform the abstract 
movements (Merleau-Ponty $1981110 /$ p. 128). ${ }^{10}$ In the second line of argument the normal performance of abstract movements is said to be assured by the body as motor power (puissance motrice, idem). In the first line of argumentation the body of Schneider is characterized in similar terms as a power over a certain world (puissance d'un certain monde, Merleau-Ponty 1981 p. 106 / p. 124). When Merleau-Ponty, after his long discussion of the Schneider case, concludes that we have finally reached an unequivocal understanding of motor intentionality as an original kind of intentionality, he characterizes the phenomena in the exact same terms he used to describe Schneider's intact grasping capacity (Merleau-Ponty 1981 p. $137 /$ p. 160). In Schneider's grasping behaviour he was said to magically anticipate the endpoint in a non-representational manner. A similar description is now given of the way a normal person is able to relate motor intentionally to objects.

We are now in a position to see that Zaner's contradiction concerns the notion of motor intentionality. Apparently motor intentionality is claimed both to be what is preserved in the Schneider case and what enables the performance of concrete behaviour and to be what is impaired in the Schneider case, an impairment which is to explain the disability to perform the abstract movements. If this is the case then it seems that either the interpretation is contradictory or it is vacuous. It is contradictory if motor intentionality is at the same time and in the same respect ascribed to and denied ascription to Schneider. It is vacuous if all that is said is that motor intentionality is present precisely when we are to perform concrete action but vanishes when we are to perform abstract actions. I think this is a real difficulty inherent in Merleau-Ponty's text but that it is possible to resolve it by modifying the positive conclusion of Merleau-Ponty's first line of argument. In the next section I focus on how the unrestricted positive conclusion of the first line of argument, which I take to be problematic, appears in Merleau-Ponty's text and how his Argument from Concrete Behaviour borrows credibility from what is in fact a misrepresentation of Goldstein's text.

\section{A confusion of the normal and the pathological}

The modest positive conclusion of the Argument from Concrete Behaviour is that at least in certain pathological cases we have evidence for a way of being directed towards objects in intentional actions that is independent of a conceptual understanding of the location of the object. Zaner's contradiction appears because Merleau-Ponty goes beyond the modest conclusion and transfers the conclusion concerning the pathological case directly to the normal case. The generalized conclusion is expressed when Merleau-Ponty, in the run of the first line of argumentation, writes that it is always our phenomenal body and never our objective body that we move (Merleau-Ponty 1981 p. $106 /$ p. 123). The example of a movement of the phenomenal body given just before the generalized conclusion is

\footnotetext{
${ }^{10}$ I use Colin Smith's translation of résultat, which I think captures the meaning of Goldstein's original presentation of the abstract movements. Goldstein speaks of Schneider's abstract movements as having a determinate purpose or objective: 'Festgelegt ist wesentlich die Erfüllung eines bestimmten Zweckes, die Erreichung eines bestimmten Zieles der Bewegung.' (Goldstein 1923, p. 179).
} 
Schneider's immediate reaching out for the point on his body where a mosquito has bitten him. Throughout the first line of argument, Merleau-Ponty's text shifts, apparently effortlessly, between descriptions of the Schneider case and general descriptions of how we normally relate to our own body and our surroundings in a non-representational manner (Merleau-Ponty 1981 pp. 105-106 / pp. 122-124).

It is in the run of the Argument from Concrete Behaviour that we find a misattribution of a quote from a text by Goldstein. Merleau-Ponty brings the following quote from Goldstein:

This is what our patient is no longer able to do. In the course of living, he says, 'I experience the movements as being the result of the situation, of the sequence of events themselves; myself and my movements are, so to speak, merely a link in the whole process and I am scarcely aware of any voluntary initiative...It all happens independently of me.'(Merleau-Ponty 1981, p. 105 / 1945, p. 122, the omission in the quote from Goldstein is Merleau-Ponty's own)

The quote is the longest and one of the most vivid expressions we are presented with qua testimony of Schneider himself. In fact, however, the quote does not contain the words of Schneider but Goldstein's first-person description of how the normal person experiences the flow of everyday routine activities. Here is the quote in its original context:

I experience the movements as being the result of the situation, of the sequence of events themselves; myself and my movements are, so to speak, merely a link in the whole process and I am scarcely aware of any voluntary initiative, really only when I explicitly focus on it. It all happens as if by itself. So the experiences of the normal person performing movements of everyday life may barely be essentially distinguishable from those of the patient inspite of his optic deficiency, as also his behaviour in such instances barely deviates from that of the normal person. (Goldstein 1923, p. 175, I have italicized the sentence left out by Merleau-Ponty as well as the sentence immediately succeeding the section he quotes. $)^{11}$

The crucial issue here is not the extent to which the misattribution is a matter of deliberate manipulation, but rather the extent to which Merleau-Ponty's argument hinges on this misidentification relative to the first person pronoun.

The misattribution appears in the text just before Merleau-Ponty shifts from giving a description of the experience of the patient to the general account given in the first person. Here Merleau-Ponty in effect attempts to transfers what already is a description of the normal case to the normal case and the intended indirect illumination of the

\footnotetext{
${ }^{11}$ I have used Smith's translation of the part of the quote used by Merleau-Ponty except for the sentence "It all happens independently of me" which I have rendered as "It all happens as if by itself". The rest of the translation is my own. Here is the original German version:
}

Ich erlebe, wie die Bewegung aus der Situation, aus der Abfolge der Geschehnisse selbst erfolgt; ich bin mit meinen Bewegungen gewissermaßen nur ein Glied in der Abfolge und werde mir der willkürlichen Innervation kaum bewußt, eigentlich nur, wenn ich mich ausdrücklich daruf besinne. Es geht alles wie von selbst. Die Erlebnisse des Normalen mögen sich so bei den Bewegungen im Leben von denen des Patienten trotz dessen Defekt im Optischen kaum wesentlich unterscheiden, wie ja auch sein Verhalten da kaum vom Normalen abweicht. (Goldstein 1923, p. 175, I have italicized the sentence left out by Merleau-Ponty as well as the sentence immediately succeeding the section he quotes.) 
normal via the more perspicuous pathological case becomes illusory. However in Goldstein's text we do find some evidence for the idea that the patient's experience of performing concrete actions corresponds to the normal subject's experience of habitual activities. As we saw in the quote above Goldstein does in fact say that the described normal experiences of the engagement in skilful everyday life activities are 'barely essentially distinguishable' from those found in the pathological case. Goldstein further writes that the patient's performance of habitual actions, such as taking out a match and lighting a lamp, are, even when performed on request, carried out just like they are by a normal person (Goldstein 1923, p. 172, p. 174).

Though Merleau-Ponty provides the Argument from Concrete Behaviour with an illegitimate air of authenticity when misattributing the quote to Schneider, it seems that he could have made the same argument without such a confusion of the normal and the pathological case. On this background it could appear as if Kelly is on the right track when he re-enacts the Argument from Concrete Behaviour in his arguments for the need to assume a level of non-conceptual motor intentionality. Kelly argues that the absorbed skilful coping activities of normal subjects involves the same kind of experience as does the concrete actions of Schneider (Kelly 2000, p. 168, Kelly 2004 p. 75). The problem, however, is that this leaves Zaner's contradiction intact. If we stick to Merleau-Ponty's unrestricted conclusion of the first line of argument we need to deny that what is missing in the Schneider case is, as otherwise claimed by Merleau-Ponty, a full-fledged version of motor intentionality. If we don't, we encounter the contradiction in question. If we follow Kelly and argue that what we find in the relevant pathological cases is a pure version of motor intentionality it seems that we are forced to claim that what is missing in such cases is a strictly conceptual level of understanding. This consequence is in fact taken by Kelly when he suggests that Merleau-Ponty's distinction between a bodily space and an objective space corresponds to a distinction between a non-conceptual egocentric and an objective and conceptual representation of space. Kelly argues that the objective understanding of space is neither sufficient nor necessary for the grasping act that can occur within an isolated non-conceptual egocentric space (Kelly 2000, p. 167, n. 33, Kelly 2004 p. 68).

I think Kelly's interpretation, which ignores Merleau-Ponty's second line of argumentation, goes against some fundamental traits of Merleau-Ponty's phenomenology. Furthermore, as I shall demonstrate, it is not as obvious as it would seem that Merleau-Ponty's Argument from Concrete Behaviour is the one which is best supported by Gelb and Goldstein's work. To support these claims I shall now turn to Merleau-Ponty's general methodological considerations.

\section{Methodological considerations}

Anthony Marcel has put the constant problem of what to infer from psychological dissociations in the following way:

whether a psychological dissociation reveals a basic separation hidden by the normal integrated functioning or whether it reflects an abnormal mode or some compensatory attempt to deal with a dysfunction. (Marcel 2003, p. 56) 
On the one hand, dissociations might reveal the possible separations of two functions that in the normal case always travel together and therefore might not even have been suspected to consist in two distinct passengers. On the other hand, the functioning which is present in the pathological case might merely reflect the fact that some normal function is disturbed and we should therefore be careful not to mistake a compensatory coping strategy for a normal function in splendid isolation. It is such a confusion Goldstein warns against when he writes that we should not mistake Schneider's swift performance of the abstract movements once he recognizes the beginning of the intended figure for the way we normally perform such actions. The precision and the uniformity of Schneider's abstract movements are exactly pathological features and therefore cannot directly tell us something about the mechanisms that enable the normal execution of such movements (Goldstein 1923, p. 178).

In his general reflections on the methodology of psychology, Merleau-Ponty emphasizes a method which seeks to make sense of the compensatory strategies observed in pathological cases via their indirect indication of fundamental features of our existence:

It is impossible to deduce the normal from the pathological, deficiencies from the substitute functions, by a mere change of signs. We must take substitutions as substitutions, as allusions to some fundamental function that they are striving to make good, and the direct image of which they fail to furnish. (Merleau-Ponty 1981, p. 107-108 / 1945, p. 125)

The general methodological conclusion, which Merleau-Ponty reaches through his analysis of the Schneider case, is that we need to develop a new method of existential or intentional analysis which can make the pathological cases intelligible as variations of the total being of the subject (Merleau-Ponty 1981, p. 59, p. 120, p. 136 / 1945, p. 71, p. 140, p. 158). The claim is that the cases cannot be made intelligible via a merely causal mode of explanation that proceeds by isolating variables that are either present or absent (Merleau-Ponty 1981 pp. 119-120 / p. 139).

In his interpretation of other aspects of Schneider's condition it is obvious that Merleau-Ponty interprets the dissociations in question as reflecting a pathological mode which by contrast can make us aware of essential features of our normal experience. He argues that the way Schneider identifies a visually presented object via conjectures and inferences can make the normal immediate configuration of the visually given evident to us:

This procedure contrasts with, and by so doing throws into relief [met en evidence] the spontaneous method of normal perception, [...].(Merleau-Ponty 1981, p. 131 / 1945, p. 153).

Neither the inferences nor the dissociated visual 'content' of the patient are elements that we should expect to find in the normal perception (Merleau-Ponty 1981 p. 137 / p. 160). When Goldstein says that only in the pathological case can we study the tactile sensations in themselves, Merleau-Ponty adds that Goldstein's own descriptions suggest that the 'pure tactile sensation' is precisely a pathological phenomenon:

The conclusion is sound, but it amounts to maintaining that the word 'touch' has not the same meaning applied to the normal as to the abnormal subject, that 
the 'purely tactile' is a pathological phenomenon which does not enter as a component into the normal experience. It is further implied that illness, by disturbing the visual function, has not disclosed the pure essences of touch, that it has indeed changed the whole of the subject's experience, or, if one prefers it put in this way, that there is not in the normal subject a tactile and also a visual one, but an integrated experience to which it is impossible to gauge the contribution of each sense. (Merleau-Ponty 1981, p. 119 / 1945, p. 138)

If we apply the integrative model implied in this quotation on the relation between the concrete and the abstract attitude this would mean that we should understand the pathological case as a case of disintegration of two attitudes and not just as the lapse of the abstract attitude. The consequence of the integrative model is that we should not expect the concrete movements of Schneider to be of the same phenomenological kind as those of the normal person moving under similar circumstances. On this model 'concrete movement' means something different when used to describe the pathological case than it does when applied in the normal case. The fact that this is the general structure of Merleau-Ponty's conception of the relation between the concrete and the abstract attitude becomes evident once we attend to his discussion of Schneider's intellectual capacities.

Merleau-Ponty argues that though Schneider's arithmetic capacity is somewhat diminished we cannot say that he is deprived of the concept of number, as he is still capable of counting visually presented objects using his fingers (Merleau-Ponty 1981 pp. 133-134 / p. 156). He further argues that in general we cannot speak of a pure concept of number, which the normal person possesses and which Schneider is then deprived of, because even in the normal case the series of numbers is a structure that is more or less (le plus et le moins) tied to melodic series of kinaesthetic experiences (Merleau-Ponty 1981 p. 134 / p. 156).

As Merleau-Ponty notes, the same integrative model is found in Goldstein's work. At one point Goldstein concludes that even the grasping-attitude of the normal requires the categorical or abstract attitude (Merleau-Ponty 1981 p. 123, n. $1 /$ p. 144, n. 1; Goldstein 1971, pp. 279-280). The interdependence between the two attitudes in the normal case is what we have already seen emphasized by Goldstein and Scheerer when they suggested that the two attitudes are related as figure and ground in the normal case (Goldstein and Scheerer 1964, p. 8).

To claim that the pathological case provides an isolated version of a highest common factor shared with the normal case would not be in accordance with Merleau-Ponty's general methodology nor with the aspects of Gelb and Goldstein's work, which he argues shows that they are on the verge of breaking with a merely causal mode of understanding (Merleau-Ponty 1981, p. 122, n. 1, p. 123 n. 1 / 1945, p. 142, n. 1, p. 144. n. 1). Nevertheless such a claim about a pure version of motor intentionality is, as we have seen, the main thrust of Merleau-Ponty's first line of argument concerning Schneider.

I think the best way to make Merleau-Ponty's first line of argument intelligible within the general framework of Phenomenology of Perception is to regard it as an attempt to employ the pathological case as a case where a certain aspect of the normal mode of motor intentionality is accentuated. On this interpretation the aspect of motor intentionality that is claimed to be highlighted in the pathological case would be the non-conceptual and non-representational directedness towards an 
object, which is then claimed to characterize the object-directed actions of the normally functioning person as well. This interpretation makes Merleau-Ponty's Argument from Concrete Behaviour an analogue to the way he argues that the synaesthetic effect of mescaline can be understood as an accentuation of a fundamental intertwinement of the senses already present in normal perception (Merleau-Ponty 1981 pp. 228-229 / pp. 264-265). Merleau-Ponty does refer to the difficulties of 'stripping pure motor intentionality naked', but such talk appears only in the context of his discussion of cases of motor apraxia, in which he argues we find motor intentionality revealed indirectly by its disturbed mode of functioning (Merleau-Ponty 1981 p. 138, n. $1 /$ p. 161, n. 1). His argument based on cases of apraxia is structurally similar to the second line of argument concerning the Schneider case. In such cases, Merleau-Ponty argues, we need to assume that it is a non-representational motor intentionality that is disturbed since they are neither cases of simple paralysis nor of disturbances of the intellectual capacity of the patient. ${ }^{12}$

After the run of the two lines of argument, Merleau-Ponty qualifies the difference between the patient and the healthy person. These qualifications make it even more evident that his interpretation is opposed to a common factor view of the experiences of the patients and of the normal subjects. Merleau-Ponty claims that only when we realize that there is a certain way of structuring one's surroundings that serves as the background for normal movement and vision, and realize that it is this structuring that is disturbed in the pathological case, will we be able to procure a coherent account of the dissociation of the grasping and the pointing attitude (Merleau-Ponty 1981 p. 115 / p. 133). Gelb and Goldstein report that when Schneider walks by the house of Goldstein he will not recognize it unless he already has the intention to pay Goldstein a visit (Merleau-Ponty 1981 p. 134 / p. 157). In accordance with this observation, Merleau-Ponty describes Schneider's condition as a contraction of the awareness of action possibilities which are present on the horizon of one's practical awareness of the world (Merleau-Ponty 1981 p. 117, p. 135, n. 3 / p. 136, p. 157, n. 5). ${ }^{13}$ This characterization of Schneider's awareness contrasts with Merleau-Ponty's description of the normal open-ended horizon that constitutes our awareness of the world as a field of action:

When I move around my house, I know without thinking about it that walking towards the bathroom means passing near the bedroom, that looking at the window means having the fireplace on my left, and in this small world each gesture, each perception is immediately located in relation to a great number of possible co-ordinates. (Merleau-Ponty 1981, pp. 129-130 / 1945, pp. 150-51)

\footnotetext{
${ }^{12}$ A homologous argument is used when Merleau-Ponty discusses the linguistic disturbances of Schneider: 'We shall have the opportunity of seeing this power, essential to speech, in cases in which neither thought nor 'motility' is noticeably affected, and yet in which the 'life' of language is impaired.' (Merleau-Ponty 1981, p. 196 / 1945, p. 228).

${ }^{13}$ It is the presence of such potential tasks or action opportunities on the horizon of one's experience of absorbed coping which Dreyfus has recently emphasized in his account of motor intentionality (Dreyfus 2007a, p. 66). Kelly, on the other hand, implicitly denies the possibility of the presence of such affordances on the horizon when he claims that we can only be motor-intentionally aware of affordances if we actually act on them (Kelly 2005, p. 19). The difference is a reflection of the fact that the authors pursue two different lines of argument corresponding to the two lines of arguments concerning the Schneider case.
} 


\section{Conclusion}

Let me sum up the conclusion of my discussion of Merleau-Ponty's arguments based on the Schneider case and of Zaner's contradiction. Merleau-Ponty downplays the differences between the pathological cases and the normal case in his Argument from Concrete Behaviour. The downplaying creates the impression that motor intentionality is claimed to be fully preserved in the Schneider case and consequently gives the appearance of a straightforward contradiction since motor intentionality is at the same time claimed to be that which is disturbed in the case. The best way to avoid the contradiction is to accentuate the differences between the concrete actions of the patient and the corresponding actions performed by the normal person, which are differences that are recognized both by Merleau-Ponty and by Gelb and Goldstein. In the light of such an accentuation of the differences we can read Merleau-Ponty's first line of argument as an attempt to highlight an aspect of normal motor intentionality and at the same time regard the mode of motor intentionality found in cases such as that of Schneider as a pathological and derivative mode. We can with Merleau-Ponty speak of a contraction of the field of action in the case of Schneider. Motor intentionality is not a question of either/or rather it is a matter of degree (comporte le plus et le moins, Merleau-Ponty 1981 pp. 121-122, p. 124, p. 134 / p. 141, p. 145, p. 156).

The analysis I have presented favours Dreyfus's recent reading of MerleauPonty's text over a reading which sticks to the Argument from Concrete Behaviour as does that of Kelly. However, the interpretation I have presented does not address the issue that has recently been debated in the exchange between Dreyfus and McDowell, i.e., the issue of whether we can understand our absorbed skilful coping activities as permeated with conceptual capacities or spontaneity in the Kantian sense (Dreyfus 2005, 2007b; McDowell 2007a, 2007b). In particular it is a further issue whether Merleau-Ponty's arguments against an intellectualism that regards our mental intentions and our bodily motility as two notionally independent items also counts against a conceptualism such as that of McDowell, which, just as Merleau-Ponty, holds that we must conceive of some of our movements as intrinsically imbued with intentionality (cf. McDowell 1994, p. 91, n. 5). Once the unrestricted conclusion of the Argument from Concrete Behaviour is forsaken the challenge faced by the nonconceptualist can, I think, be sharpened. The challenge is to show why we should not regard the disintegration of motility and intellectual capacities found in certain pathological cases as a disintegration of an explanatory primary co-operation of motility and spontaneity, rather than as a disturbance of an autonomous level of nonconceptual intentionality distinct from the level of conceptual capacities.

Acknowledgements The author wishes to thank Thomas bassbøl, Finn Collin, Thor Grünbaum, Lisa Käll, Dorothée Legrand, Søren Overgaard and Dan Zahavi for valuable comments on earlier versions of this paper. I would also like to thank the two anonymous reviewers for their helpful comments as well as the audiences at the 2nd Annual Conference of the Nordic Society for Phenomenology (Stockholm 2004), at the 10th Gathering of the Association for the Scientific Study of Consciousness (Oxford 2006) and at the 9th International Conference on Philosophy, Psychiatry and Psychology, (Leiden 2006). The research for this paper was funded by the Danish Research Council for Culture and Communication. 


\section{References}

Baldwin, T., (2007). Speaking and spoken language. In T. Baldwin (Ed.), Reading Merleau-Ponty. London and New York: Routledge

Bermúdez, J. L. (2005). The Phenomenology of Bodily Awareness. In D. W. Smith, \& A. L. Thomasson (Eds.), Phenomenology and Philosophy of Mind. Oxford: Oxford University Press.

Braddock, G. (2001). Beyond reflection in naturalized phenomenology. Journal of consciousness studies, 8, 11. Brewer, B. (1993). The Integration of Spatial Vision and Action. In N. Eilan, R. McCarthy, \& B. Brewer (Eds.), Spatial Representation. Oxford: Oxford University Press.

Cole, J. (2008). Phenomenology, neuroscience and impairment. Abstracta, Special Issue II, 20-33.

Dreyfus, H. (2005). Overcoming the Myth of the Mental - APA Pacific Division Presidential Address, http://ist-socrates.berkeley.edu/ hdreyfus/pdf/Dreyfus\%20APA\%20Address \%20\%2010.22.05\%20. pdf (last checked 2009-20-01). A shorter version is printed in Topoi 2006, 25: 43-49.

Dreyfus, H. (2007a). Reply to Romdenh-Romluc. In T. Baldwin (Ed.), Reading Merleau-Ponty. London and New York: Routledge.

Dreyfus, H. (2007b). Response to McDowell. Inquiry, 50(4), 371-377.

Farah, M. (2004). Visual Agnosia. Cambridge, MA: MIT.

Gallagher, S. (2003). Bodily self-awareness and object perception. Theoria et historia scientiarum, 3(1), 55-70.

Goldenberg, G. (2003). Goldstein and Gelb's Case Schn.: A classic case in neuropsychology? In C. Code, C-W. Wallesch, Y. Joanette \& A. R. Lecours (eds), Classic Cases in Neuropsychology (Vol. II). Psychology, Taylor \& Francis.

Goldstein, K. (1923). Über die Abhängigkeit der Bewegungen von optischen Vorgängen. Bewegungsstörungen bei Seelenblinden. Monatschrift für Psychiatrie und Neurologie, Festschrift Liepmann.

Goldstein, K. (1971). Über Zeigen und Greifen. In A. Gurwitsch, E. M. Goldstein Haudek, \& W. E. Haudek (Eds.), Selected Papers/Ausgewählte Schriften. The Hague: Martinus Nijhoff.

Goldstein, K., \& Gelb, A. (1918). Psychologische Analysen hirnpathologischer Fälle auf Grund von Untersuchungen Hirnverletzer. Zeitschrift für die Gesamte Neurologie und Psychiatrie, 41, 1-142.

Goldstein, K., \& Scheerer, M. (1964). Abstract and Concrete Behavior. An Experimental Study With Special Tests. Evanston, Illinois: Northwestern University Reprint of Pscyhological Monographs, 1941, vol. 53, no. 2 .

Grünbaum, T. (2008). The body in action. Phenomenology and the Cognitive Sciences, 7/2, 243-261.

Hornsby, J. (1997). Simple Mindedness. Cambridge, MA: Harvard University Press.

Hornsby, J. (1998). Dualism in Action. In A. O'Hear (Ed.), Current Issues in Philosophy of Mind. Cambridge: Cambridge University Press.

Kelly, S. D. (2000). Grasping at straws: Motor Intentionality and the Cognitive Science of Skilled Behaviour. In M. Wrathall, \& J. Malpas (Eds.), Heidegger, Coping and the Cognitive Sciences: Essays in Honor of Hubert L. Dreyfus (vol. II, pp. 161-177). Cambridge, MA: MIT.

Kelly, S. D. (2004). Merleau-Ponty on the body. In M. Proudfoot (Ed.), The Philosophy of the Body (pp. 62-76). London: Blackwell.

Kelly, S. D. (2005). Closing the gap: phenomenology and logical analysis. The Harvard Review of Philosophy, xiii, 2.

Landis, T., Graves, R., Benson, F., \& Hebben, N. (1982). Visual recognition through kinaesthic mediation. Psychological Medicine, 12, 515-531.

Marcel, A. (2003). The sense of agency: Awareness and Ownership of Action. In J. Roessler, \& N. Eilan (Eds.), Agency and Self-Awareness. Oxford: Oxford University Press.

Marotta, J. J., \& Behrmann, M. (2004). Neuropsychologia, 42, 633-638

McDowell, J. (1994). Mind and World. Cambridge, MA: Harvard University Press.

McDowell, J. (2007a). What Myth? Inquiry, 50(4), 338-351.

McDowell, J. (2007b). Response to Dreyfus. Inquiry, 50(4), 366-370.

Merleau-Ponty, M. (1942). La structure du comportement. Paris: Quadrige/Presses Universitaires de France.

Merleau-Ponty, M. (1945). phénoménologie de la perception.Gallimard.

Merleau-Ponty, M. (1981). Phenomenology of Perception. In C. Smith (translation). London: Routhledge \& Kegan Poul.

Siewert, C. (2005). Attention and Sensorimotor intentionality. In T. Carman \& M. B. N. Hansen (eds), The Cambridge Companion to Merleau-Ponty. Cambridge University Press.

Waldenfels, B. (2000). Das leibliche Selbst. Frankfurt am Main: Suhrkamp Verlag.

Zaner, R. M. (1964). The problem of embodiment, some contributions to a phenomenology of the body. Phaenomenologica 17. The Hague: Martinus Nijhoff. 